\title{
Conproving teaching efficiency on medical universities - A comparative study of Hungarian and foreign medical university students' feedbacks regarding learning by KOLLAR method
}

\author{
Janos Kollar ${ }^{1}$, Bernadett Babusa ${ }^{1}$, Adrienne Stauder ${ }^{1}$, János Pilling ${ }^{1}$, \\ Réka Cserepes ${ }^{2}$, Edit Czeglédi ${ }^{1}$
}

'Institute of Behavioral Sciences, Semmelweis University, Budapest, Hungary.

${ }^{2}$ Institute of Behavioral Sciences, Debrecen University, Debrecen, Hungary.

Address for correspondence: Janos Kollar, Institute of Behavioral Sciences, Semmelweis University, Budapest, Hungary,

janoskollar@gmail.com

Received: November 5, 2015 Accepted: December 23, 2015 Published: April 7, 2016

\begin{abstract}
Objective. KOLLAR method is a learning and teaching promoting method that frames the generally missing elements into education. The word is an acronym namely $K O$ is for Keys of Originality, $L$ is for Learning, $L$ is for Lecturing, $A$ is for Application of social media, and $\mathrm{R}$ is for Relaxation. The aim of the cross-sectional study was the assessment of the evaluation of the KOLLAR method among medical university students during the development and progress of the method. Methods. Participants were first and third grade medical university students of Debrecen University, $(n=1893$; $56 \%$ was foreign student). The evaluation of the method was rated on a six-item scale, each item scored from 0 to 6 . The items were analyzed separately, and as an aggregated score. Data were collected between the years 2002-2012. Results. According to the results of analyses using the aggregated index of evaluation (principal component, $R^{2}=59 \%$ ), the Hungarian, the first year, and the physiotherapy students evaluated the method more positively than the foreign $(Z=$ 4.460, $p<.001)$, the third year $(Z=-3.994, p<.001)$, and the medical students $\left(H_{(2)}=10.014, p=.007\right)$. The evaluation of the courses become better during the years. Conclusions. The evaluation of the KOLLAR method was generally favorable among medical university students which demonstrated an improving trend during the years of crystallization process.
\end{abstract}

KEY WORDS: Education; Learning; Medical; Creativity; Relaxation

\section{INTRODUCTION}

Medical university students seem to be overwhelmed by the great amount of information needed to acquire during their studies. University studies are the sources of different stresses affecting learning abilities, achievements in professional and private life and also health of the students [1-3]. The urge of proper teaching methods is compelling for helping both students and teachers to feel effective on the field of medical education. Old, sometimes even outdated and new methods exist side by side in the educational system. Unfortunately the old ones are often represented by well respected professors grew up in the ancient era of learning and students of the $21^{\text {st }}$ century are compelled to find their own learning styles without getting proper help from their teachers. Thus the methods offered by respected university teachers often don't serve the students need for effective learning.

In our view there are five areas of teaching and learning can be distinguished as needing urgent improvement. The first is creativity improvement since most of the educational system support "reproduction" instead of "production".
Although academic medicine provides informal training in creativity and innovation, it has yet to incorporate into medical education [4]. The second area is the field of learning. Most of the students use old methods they got used to without having the remotest idea about the existence of learning strategies better meeting their own requirements and claims [5-6]. The third area to be improved is the style of lecturing. Grabbing the attention of the audience, avoiding the usual presentation "pitfalls", overcoming "stage fright" etc. and acquiring knowledge about the latest presentation software types are essential skills necessary for effective education [7-9]. The fourth focus area is generally better known by medical students than medical teachers. This is the utilization of social media in learning [10-11]. Finally the fifth area is relaxation. Medical university students consider it as one of the most important method to cope with stress [12] although only a few of them know any effective relaxation techniques.

The general aims of the study were the introduction of the KOLLAR method and the evaluation of this new learning and teaching model among medical university students. 


\section{METHODOLOGY AND METHODS}

\section{Introduction of the KOLLAR method}

The KOLLAR method focuses on the development of the five areas mentioned above. This is an acronym, namely $\mathrm{KO}$ is for Keys of Originality, L is for Learning, $\mathrm{L}$ is for Lecturing, A is for Application of Social Media and R is for Relaxation. The method was developed by the author, Janos Kollar, who tested it on his medical university students during his teaching career on Debrecen University between 2001 and 2012. The method was implemented in the teaching program of different subjects (Medical Communication, Medical Psychology, Music therapy, Presentation) [13]. The Medical Communication course is focused on effective strategies to develop a trustful doctor-patient relationship and to enhance doctor-patient collaboration [14]. The Medical Psychology course deals with health psychological perspectives in medical practice. The Music Therapy course introduces the use of music as a possible therapeutic method. The Psynema course includes thought-provoking discussions based on movies dealing with different aspects of the doctor-patient relationship. Finally, on the presentation course the basic rules of giving lectures and presentations are introduced to the students and they also have the possibility to practice some related skills.

$\mathrm{KO}-$ Keys of Originality. This element of the method helps the teacher focusing on improving the creativity of the students by applying creative techniques such as divergent thinking, problem solving and creative production [15]. Students are encouraged to disclose their opinion about the topics discussed and to bring arguments supporting their opinion even in contrary to their fellow students or to the lecturer. Small group discussions and organizing "pro" and "contra" groups are useful techniques to improve the quality of such debates. The teacher should also teach some simple creativity development techniques that can become part of the everyday practice (eg. journaling, learning by drawing, associational thinking, mind mapping etc.). Some short brain teasers motivating the students to think "out of the box" should also be built into the regular seminars. Such short brain teasers can be found in great abundance on the internet.

L - Learning. Learning methods fitting into somebody's learning style can help to make the process of learning as enjoyable and easy as possible. Such techniques can help to better organize and structure memory, to increase retention and to enhance recall of information and to help finding associations between different types of learning material. First the lecturer should offer a wide range of mnemotechnic methods like for example interactive drawing [16], PQRST (Preview, Question, Read, Summarize, Test) technique, method of loci (using visual coding to organize and recall information), story building (composing stories including the information to be recalled from memory), $\mathrm{ABC}$ method (visualizing the shape of letters in a word to remember), learning numbers etc. [17]. It is also advisable to call the attention to the importance of time management [18], the importance of emotional inputs during learning [19] and the effects of biological factors on learning such as nutrition, regular exercising and proper breathing techniques.

$\mathrm{L}$ - Lecturing. Besides that all the teachers should know the basic rules of lecturing it is a well-known fact that the best way of learning is giving presentations. Students should make their own presentations about the material discussed meanwhile the teacher should teach them the basic rules of creating and holding presentations including methods for overcoming nervousness, keeping time frames, the different ways for grabbing the attention of the audience, visualization methods, the common pitfalls of making PowerPoint presentations etc. During their studies the students should also become familiar with the latest presentation software types like Prezi (http://prezi.com) and Leonar3Do (http://leonar3do.com).

A - Application of Social Media. One of the most challenging and promising possibility of the $21^{\text {st }}$ century is applying the advantages of Social Media in teaching. More and more teachers and researchers draw the attention of lecturers and students to the risks and opportunities of this exceptional approach of learning [20-22]. Both medical university students and teachers should know how to find relevant and reliable information on the World Wide Web by using for example RSS, how to use the advantages of free information sites for learning and for helping patients, how to exploit the possibilities of Web 2.0 and Web 3.0 (thematic and semantic web) and it is also advisable to know how to organize virtual conferences in the cyberspace.

$\mathrm{R}$-Relaxation. Medical university students are complaining about a high level of distress all over the world [23-25]. The advantages of relaxation should be utilized to a greater extent than it is applied nowadays. Students should learn and practice 1, 3 and 7 minute long relaxation exercises during their studies. Such exercises don't require significant amount of time but can multiply the efficiency by reducing stress and attention distraction and by increasing positive $\operatorname{mood}[26]$.

The aim of the cross-sectional study was the assessment of the evaluation of the KOLLAR method among medical university students during the development and progress of the method.

\section{Participants and procedure}

All of the participants $(n=1893)$ in the cross sectional survey were $1^{\text {th }}$ and $3^{\text {th }}$ year medical university students of Debrecen University, Medical and Health Science Centre (Debrecen, Hungary). We selected first and third year 
students because Medical Communication and Medical Psychology is included only in the first and third year students' curriculum respectively. More than half of the students were foreigners $(56.1 \%, n=1062)$. Relating to the year and faculty of education $73.7 \%(n=1396)$ of the participants provided information. Three-fourths of the respondents $(73.2 \%, n=1022)$ were first year students. The majority of them $(84.3 \%, n=1176)$ studied on the faculty of general medicine, $14.8 \%(n=207)$ on dentistry, and $0.9 \%$ $(n=13)$ on physiotherapy.

Students were invited to complete a paper-and-pencil questionnaire anonymously, which took approximately 5 minutes. They were not remunerated for participation and taking part in the study was voluntary. A short, sixitem questionnaire concerning the evaluation of the course was constructed for the purpose of this study: 1) Overall evaluation of the seminars; 2) How the aims of the seminars and the related exercises met my requirements; 3 ) Individual involvement on the seminars; 4) The involvement of the group on the seminars; 5) The usefulness of the seminars; 6) Evaluation of the seminar teacher. Items were rated on a 7-point Likert-type scale $(0=$ weak, $6=$ excellent $)$, with higher scores reflecting higher satisfaction.

Data were collected between the years 2002-2012. We do not have any data from those students who refused the participation in the study.

\section{Data analyses}

Based on the fact that the distribution of the variables was not normal, Comparison of evaluation items was performed by repeated measures ANOVA on ranks. To compare the groups also non-parametric tests (i.e. Mann-Whitney Test, Kruskal-Wallis Test) were used. Principal component analysis was used for data reduction to create a composite value of the six items. Time trends of the aggregated evaluation of the course were tested with Kruskal-Wallis Test and two-way rank ANOVA. Statistical analyses were performed using the SPSS 21.0 and the ROPstat software packages.

\section{RESULTS}

\section{Characteristics of the sample}

Participants learned by the KOLLAR method within the framework of different university courses: $49.7 \%$ on Medical Communication, 24.0\% on Medical Psychology, 8.6\% on Music Therapy, $7.1 \%$ on Psynema, and $10.6 \%$ on Presentation course. The proportion of the Hungarian and foreign students on the various courses differed significantly $\left(\chi_{(4)}^{2}=52.024, p<.001\right)$.

Over the years of the study the number of the participants was the lowest in $2008(5.9 \%, n=111)$ and the highest in $2002(14.2 \%, n=268)$. Figure 1 presents the percentage of the participants over the years from 2002 to 2012.

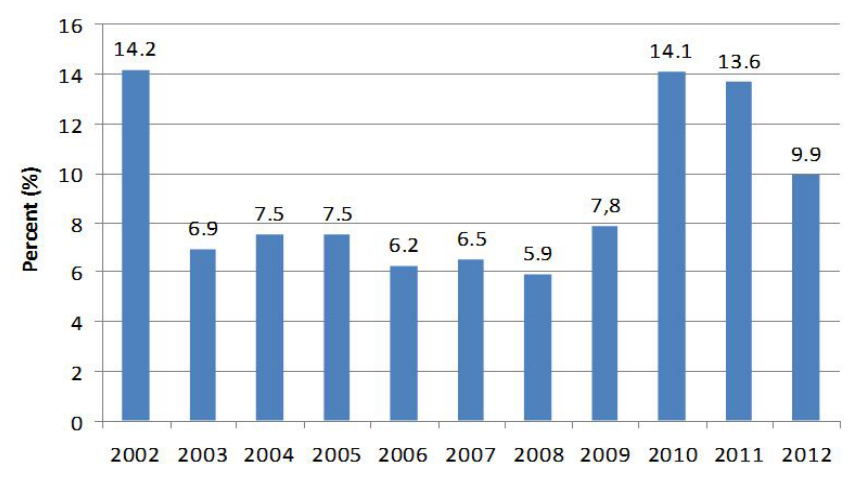

Figure 1. The proportion of participants over the study years

\section{Basic statistics of evaluation}

Figure 2 shows the mean values of evaluation items with their $95 \%$ confidence intervals. Results of ANOVA on ranks indicated significant differences between evaluation items $\left(\mathrm{rF}_{(5)}=666.210, p<.001\right)$. The most favorable result was the evaluation of the teacher $(M=5.6, S D=0.70)$ and the least one was the individual participation $(M=4.3, S D=1.23)$. According to the results of the post hoc Tukey-type pairwise comparison of rank means the only items showing no significant differences were the „Met the requirements” and the "Usefulness".

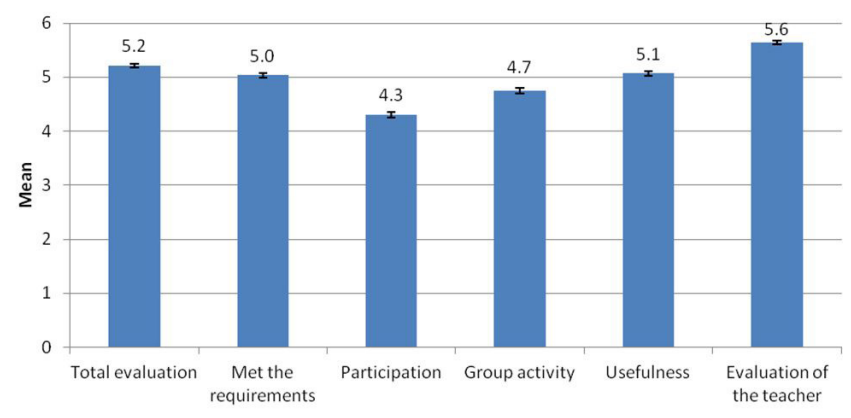

Figure 2. Mean values of evaluation items with their $95 \%$ confidence intervals

\section{Comparison of course evaluation between Hungarian and foreign students}

The Hungarian students evaluated the courses significantly more favorably than the foreign students on four of the six items (Total evaluation; Met the requirements; Usefulness; Satisfaction with the teacher), the foreign students were more satisfied with Participation, and there was no difference in the evaluation of group activity $(Z=-1.950$, $p=.051$; see Table 1).

The principal component analysis of the six-item resulted in one principal component $\left(\mathrm{R}^{2}=52.1 \%\right)$. The loading of the item "students' participation" on the principal component was not satisfactory $(<0.50)$. It has to be noted that the phrasing of this item was ambiguous since it refers to the participation of the students and also to the students' involvement in the course. Based on the low principal component loading and the ambiguity we decided 
to exclude this item and the principle component analysis was performed with the remaining five items. This analysis also resulted in one principal component. The principal component loadings ranged between .57-.85 and the total variance accounted for $59.0 \%$. Higher score on the principal component reflects a favorable evaluation. In line with the above mentioned results Hungarian students scored significantly higher on the principal component compared to the foreign students $(Z=-4.460, p<.001$, Table 2.).

\section{Comparison of the course evaluation among subgroups}

First year students evaluated the courses more favorably than the third year students $(Z=-3.994, p<.001)$. Comparing the different faculties, physiotherapy students scored significantly higher on course evaluation than general medicine and dentistry students $\left(\mathrm{H}_{(2)}=10.014\right.$, $p=.007)$. Results are detailed in Table 2 .

There were also significant differences in the evaluation of the various courses $\left(\mathrm{H}_{(4)}=47.671, p<.001\right)$. Results of the pairwise post-hoc tests revealed that the Music Therapy and Psynema courses had significantly higher positive evaluation than the Medical Communication, Medical Psychology, and Presentation seminars. However, there was no significant difference between the evaluation of Music Therapy and Psynema courses (Figure 2).

\section{Time trends in course evaluation}

Course evaluation changed significantly over the years $\left(\mathrm{H}_{(10)}=148.964, p<.001\right)$. To summarize, the satisfaction with the courses improved over the years; however, there was no significant difference between the means in the last five years. Means are presented in Figure 3.

According to the results of the two-way rank ANOVA, besides the significant main effect of the year of the survey $\left(\mathrm{F}_{(9)}=14.004, p<.0001\right)$ and the nationality $\left(\mathrm{F}_{(1)}=25.884\right.$, $p<.0001)$, the interaction of these two variables also proved to be significant $\left(\mathrm{F}_{(9)}=4.165, p<.0001\right)$. Figure 4 demonstrates that the changes in course evaluation over the years were greater among foreign students compared to the Hungarian students.

Table 1. Comparison of course evaluation items between Hungarian and foreign students

\begin{tabular}{|c|c|c|c|c|}
\hline Variables & $\begin{array}{l}\text { Total sample } \\
\qquad(n=1893) \\
\text { mean }(S D)\end{array}$ & $\begin{array}{l}\text { Hungarian students } \\
\qquad(n=831) \\
\text { mean }(S D)\end{array}$ & $\begin{array}{l}\text { Foreign students } \\
\qquad(n=1062) \\
\text { mean }(S D)\end{array}$ & Z \\
\hline Total evaluation & $5.2(0.85)$ & $5.3(0.76)$ & $5.1(0.90)$ & $-4.929^{\star * *}$ \\
\hline Met the requirements & $5.0(1.00)$ & $5.2(0.86)$ & 4.9 (1.09) & $-4.503^{* * *}$ \\
\hline Participation & $4.3(1.23)$ & $4.1(1.17)$ & $4.5(1.24)$ & $-7.367^{* * *}$ \\
\hline Group activity & $4.7(1.07)$ & $4.7(1.00)$ & $4.8(1.13)$ & $-1.950^{+}$ \\
\hline Usefulness & $5.1(1.08)$ & $5.3(0.88)$ & $4.9(1.18)$ & $-7.094^{* * *}$ \\
\hline Evaluation of the teacher & $5.6(0.70)$ & $5.7(0.58)$ & $5.6(0.77)$ & $-2.910^{* *}$ \\
\hline
\end{tabular}

Note: ${ }^{+} p<.10,{ }^{* *} p<.01,{ }^{* \star *} p<.001$.

Table 2. Comparison of course evaluation in respect of nationality, year of medical school, and faculty

\begin{tabular}{llll}
\hline & Groups & Mean $(S D)$ & Test statistics \\
\hline Nationality & Hungarian $(n=823)$ & $0.15(0.84)$ & Z=-4.460*** \\
& Foreign $(n=1036)$ & $-0.12(1.10)$ & $0.23(0.97)$ \\
Year of medical university & First year $(n=1004)$ & $-0.24(1.13)$ & Z=-3.994*** \\
& Third year $(n=370)$ & $-0.07(1.06)$ & \\
Faculty & General medicine $(n=1161)$ & $0.04(0.81)$ & $\mathrm{H}_{(2)}=10.014^{* *}$
\end{tabular}

Note: ${ }^{* *} p<.01,{ }^{* * *} p<.001$ 


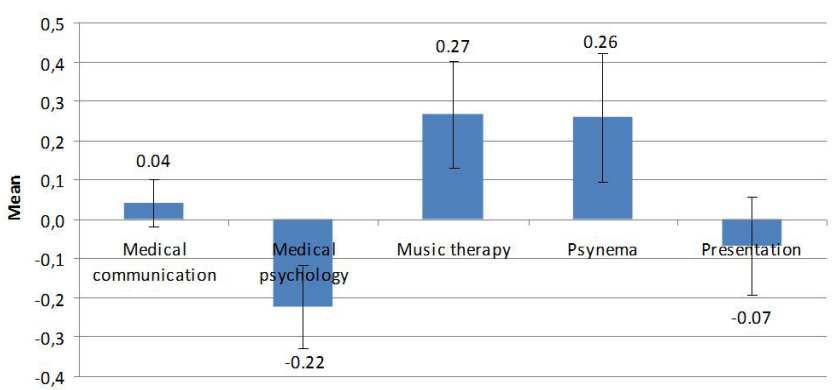

Figure 3. The evaluation of different university courses. The figure presents $95 \%$ confidence intervals of the means of principal components.

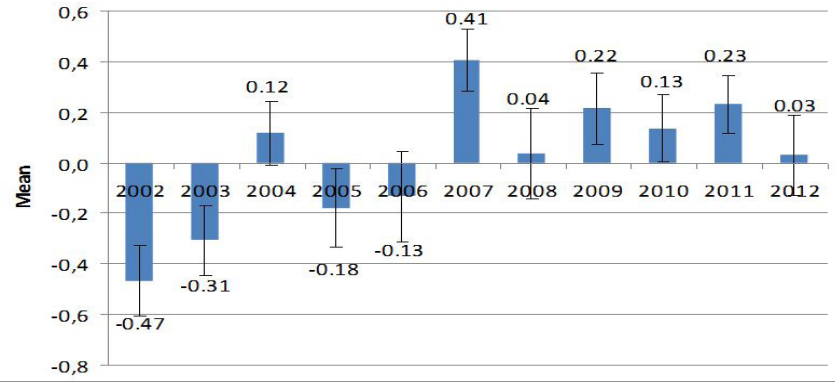

Figure 4. Course evaluation during the years. The figure presents $95 \%$ confidence intervals of the means of principal components.

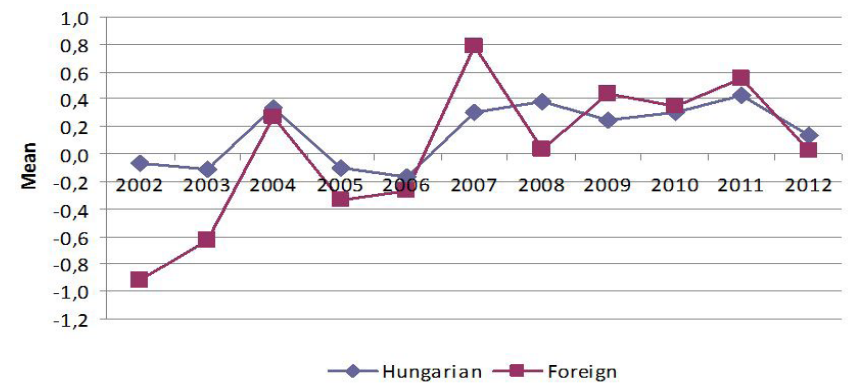

Figure 5. Changes in course evaluation over the years according to the nationality of the students

\section{DISCUSSION}

Nowadays many questions have to be addressed when faced with the rapid changes in education and technology. New methods of teaching have to improve the quality of education, enhance teaching effectiveness, and involve students in educational process. Several attempts were already made for estimating the effects of different techniques serving the improvement of the quality of teaching and learning. Ness [4] underlines the importance of teaching creativity and innovative thinking in medicine and health sciences stressing that such courses improve thinking skills, attitudes, and performance. Courneya [27] draws the attention to the significance of art based learning as a tool for improving creativity in medical education. Regarding the relation of learning styles with student satisfaction and academic achievement the first study was published by Gurpinar et al [28] but their study was carried out with the participation of only 170 first-year medical students. Our research was focusing on similar goals but the number of participants was significantly higher. Mayer et al [29] analyzed the advantages and drawbacks of applying the innovations of social media in practice of doctors and medical students highlighting the relevance of maintaining professional behavior in the environment of increasing use of internet in medical profession. The effects of group study skills counseling and applied relaxation on study behaviors and test anxiety in medical and dental students were investigated by Schroeder [30] highlighting the importance of learning and practicing relaxation on the course of the medical student studies.

Hungarian and foreign students $(n=1893)$ of the Debrecen University, Faculty of Medicine were involved in our crosssectional study. According to the results of analyses using the aggregated index of evaluation, the Hungarian, the first year, and the physiotherapy students evaluated the method more positively than the foreign, the third year, and the medical university student counterparts. Moreover, the KOLLAR method was highly appreciated especially in Music Therapy and Psynema courses. The possible explanation is likely that Music Therapy and Psynema courses are elective courses having special structure on the university, meaning that during these courses the teachers do not have to put extra effort to overcome the natural resistance of students experienced in some cases of compulsory courses. The personality of the teacher had a huge impact on the final evaluation of the courses. During the teaching process the students could feel respect from their teacher who asked them about their personal opinion about the course regularly. The regular feed-backs helped to create a warm, enthusiastic and professional environment. Their own individual participation is always underestimated by the students. A reason of it is the increasing number of students per groups. The number of group members should not exceed 15 people. Unfortunately because of the poor circumstances (lack of trained professional teachers, lack of room, lack of proper technical conditions) most of the time it is not feasible.

It seems that the Hungarian students were more open to the courses than the foreign ones. Students coming from different countries were more critical presumably because of their previous school experiences. The foreign students had to acquire a different style of learning (most of the time the Hungarian educational standards were higher than the ones they experienced in their home countries). On the other hand a lot of foreign students had already some life experiences making them more critical. Their opinions helped the shaping of the KOLLAR-method significantly.

First year medical students meet a lot of subject difficult to learn. It can make them disappointed and stressed. The 
KOLLAR-method is a fresh and enjoyable experience for them comparing the old teaching styles. The contrast effect is high and it can be the reason why the first year students evaluate the courses lead by the KOLLAR-method more favorable than the third year ones.

We couldn't find the explanation why students studying physiotherapy scored significantly higher on course evaluation than general medicine and dentistry students. Probably they created a more cohesive group than other students did and such unity within the group helped them significantly to enjoy the meetings.

During a decade of data collection the course evaluation become more favorable as compared to the beginning, although it has stagnated in the last five years. It is possible that the KOLLAR method attained its current form by the last five years. There might be also a ceiling effect, the students' satisfaction would never be maximal.

On the basis of the attempts and research works it can be concluded that several authors consider the different elements of KOLLAR method important nevertheless none of them was focusing on all of the elements thus their approach is not as complex as ours.

\section{CONCLUSIONS}

The innovative KOLLAR method is a learning and teaching promoting method that brings in the generally missing elements into education, considerably enhancing the effectiveness of teaching and learning alike.

To summarize the results, the evaluation of KOLLAR method was highly favorable among students. Based on the maximum achieved six-point score on the items, the average assessment of all aspects exceeded four points. The assessment of four out of six aspects achieved five points. The most favorable result was the evaluation of the teacher and the least one was the individual participation.

Several limitations of the study have to be acknowledged. The first limitation of the study is that in order to ensure the highest level of anonymity, no data were collected from respondents relating to gender and nationality; therefore possible gender and nationality differences remain unknown. This is the reason why we had no information about socio-demographic characteristics of respondents either. Second, relating to the year of medical university and faculty a quarter of the sample $(26.3 \%, n=497)$ failed to provide data. Because of the high proportion of missing data and the low sample size of some sub-groups, eg. the under-representation of the physiotherapy students the statistical power is somewhat reduced, therefore it was not possible to test the potential predictors of the evaluation of the KOLLAR method by multivariate models.

We can conclude that the evaluation of KOLLAR method is generally favorable among medical students and we demonstrated an improving trend during the years of the crystallization process. The method can be integrated not only into the courses designed on the basis of this approach (e.g., Music Therapy) but also in traditional courses. Our results support the reasonableness of the dissemination and the efficacy studies of the method. Future plans related to the KOLLAR method are regular update in the area of the internet (social media), the integration of the method into other compulsory and elective courses, and the introduction of different elements of the method in teacher trainings.

\section{COMPETING INTERESTS}

The authors declare that they have no competing interests.

\section{ETHICAL APPROVAL}

This type of research do not require ethical approval.

\section{AUTHORS' CONTRIBUTIONS}

All authors contributed to the critical revision of the manuscript and approved the final version for publication. JK was chiefly responsible for the study conception and design, data acquisition and interpretation. BB and RCs made substantial contributions to the study conception, data acquisition and interpretation, and the drafting of the paper. ECz analysed the data. JK drafted the paper and AS and JP critically revised the draft.

\section{ACKNOWLEDGEMENT}

We would like to thank to Professor Peter Molnar, Founding Chair of the Department of Behavioral Sciences University Medical School, Debrecen for his guidance and all of the students who participated in this study.

\section{FUNDING}

None

\section{REFERENCES}

1. Finkelstein C, Brownstein A, Scott C, Lan YL. Anxiety and stress reduction in medical education: an intervention. Med Educ 2007; 41:258-264.

2. Rosenzweig S, Reibel DK, Greeson JM, Brainard GC, Hojat M. Mindfulness-based stress reduction lowers psychological distress in medical students. Teach Learn Med, 2003;15:88-92.

3. Shapiro SL, Schwartz GE, Bonner G. Effects of mindfulness-based stress reduction on medical and premedical students. J Behav Med 1998;21:581-599.

4. Ness RB. Teaching creativity and innovative thinking in medicine and the health sciences. Acad Med 2011;86:1201-1203.

5. Samarakoon L, Fernando T, Rodrigo C. Learning styles and approaches to learning among medical undergraduates and postgraduates. BMC Med Educ 2013; doi: 10.1186/1472-6920-13-42.

6. Shukr I, Zainab R, Rana MH. Learning styles of postgraduate and undergraduate medical students. J Coll Physicians Surg Pak, 2013;23:25-30.

7. Malik AS, Malik RH. Twelve tips for effective lecturing in a PBL curriculum. Med Teach 2012;34:198-204. 
8. Shahidullah SM, Haque MM, Nasreen SA, Sultana S. Style of lecturing of medical teacher - an evaluation by medical students of Mymensingh Medical College. Mymensingh Med J 2006;15:120-123.

9. White G. Interactive lecturing. Clin Teach 2011:8:230-235.

10. George DR, Dreibelbis TD, Aumiller B. How we used two social media tools to enhance aspects of active learning during lectures. Med Teach 2013;35:985-988.

11. Santoro E, Quintaliani G. Using web 2.0 technologies and social media for the nephrologist. G Ital Nefrol, 2013;30: pii: gin/30.1.6.

12. Pereira MA, Barbosa MA. Teaching strategies for coping with stress-the perceptions of medical students. BMC Med Educ 2013;13:50.

13. Kollár J, Meskó B. Revolution in education - New possibilities in education of medical students. Med Teach 2011;33(8):685-686.

14. Pilling, J. The doctor-patient consultation. In: Pilling J (ed) Medical Communication, Medicina, Budapest, pp 42-62, 2011.

15. Ness RB. Teaching creativity and innovative thinking in medicine and the health sciences. Acad Med 2011;86:1201-1203.

16. Campos A, Amor A, Gonzalez MA. Presentation of keywords by means of interactive drawings. Span J Psychol 2002;5:102-109.

17. Metzig W, Schuster M. Tanuljunk meg tanulni! [Learn to learn!] Medicina, Budapest, , pp 125-128, 2003.

18. Pugsley L. Study effectively. Educ Prim Care 2009:20:195-197.

19. Joffily M, Coricelli G. Emotional valence and the free-energy principle. PLoS Comput Biol 2013;9:e1003094.

20. George DR, Green MJ. Beyond good and evil: exploring medical trainee use of social media. Teach Learn Med 2012;24:155-157.

21. Hempel G, Neef M, Rotzoll D, Heinke W. Study of medicine 2.0 due to Web 2.0?! - risks and opportunities for the curriculum in Leipzig. GMS Z Med Ausbild 2013;30:Doc11.

22. Kind T, Patel PD, Lie D, Chretien KC. Twelve tips for using social media as a medical educator. Med Teach 2013; doi: 10.3109/0142159X.2013.852167

23. Afzal H, Afzal S, Siddique SA, Naqvi SA. Measures used by medical students to reduce test anxiety. J Pak Med Assoc 2012;62:982-986.

24. Jurkat $H$, Hofer S, Richter L, Cramer M, Vetter A. Quality of life, stress management and health promotion in medical and dental students. A comparative study. Dtsch Med Wochenschr 2011;136:1245-1250.

25. Kohls N, Bussing A, Sauer S, Riess J, Ulrich C, Vetter A, Jurkat HB. Psychological distress in medical students - a comparison of the Universities of Munich and Witten/Herdecke. Z Psychosom Med Psychother 2012;58:409-416.

26. Jain S, Shapiro SL, Swanick S, Roesch SC, Mills PJ, Bell I, Schwartz $\mathrm{GE}$. A randomized controlled trial of mindfulness meditation versus relaxation training: effects on distress, positive states of mind, rumination, and distraction. Ann Behav Med 2007:33:11-21.

27. Courneya CA. On teaching confidence and creativity. Med Educ 2011:45:1070-1071.

28. Gurpinar E. Alimoglu NK, Mamakli S, Aketkin M. Can learning style predict student satisfaction with different instruction methods and academic achievement in medical education? Adv Physiol Educ 2010;34:192-196.

29. Mayer MA, Leis A, Mayer A, Rodriguez-Gonzalez A. How medical doctors and students should use Social Media: a review of the main guidelines for proposing practical recommendations. Stud Health Technol Inform 2012;180:853-857.

30. Schroeder DG. The effects of group study skills counseling and applied relaxation on study behaviors and test anxiety in medical and dental students. Annu Conf Res Med Educ 1980;19:175-80.

(C) SAGEYA. This is an open access article licensed under the terms of the Creative Commons Attribution Non-Commercial License (http://creativecommons.org/licenses/by-nc/3.0/) which permits unrestricted, noncommercial use, distribution and reproduction in any medium, provided the work is properly cited.

Source of Support: Nil, Confl ict of Interest: None declared 